\title{
NEUROPROTECTIVE EFFECT OF EPALRESTAT ON MEMORY IMPAIRMENT IN STREPTOZOTOCIN-INDUCED TYPE-2 DIABETIC RATS USING DIFFERENT BEHAVIORAL MODELS
}

\author{
SHRUTI JAISWAL ${ }^{1}$, TORGAL SS ${ }^{1 *}$, SANJAY MISHRA ${ }^{2}$ \\ ${ }^{1}$ Department of Pharmacology, J. N. Medical College, KLE Academy of Higher Education and Research (KLE University), Nehru Nagar, \\ Belagavi, Karnataka, India, ${ }^{2}$ Dr. Prabhakar Kore Basic Science Research Center, KLE Academy of Higher Education and Research (KLE \\ University), Nehru Nagar, Belagavi, Karnataka, India. Email: drtorgal@gmail.com
}

Received: 25 October 2017, Revised and Accepted: 23 November 2017

\section{ABSTRACT}

Objective: The present study was designed to evaluate the protective effects of epalrestat (EPS) on memory and learning in type-2 diabetes.

Methods: Sixty percent high-fat diet for 2 weeks and a single dose of streptozotocin (35 mg/kg, ip) was used to induce memory impairment in rats. Once the diabetes is confirmed, test drug (EPS - 13.5, 27, and $54 \mathrm{mg} / \mathrm{kg}$, oral) and donepezil (1 mg/kg, oral) were administered to different groups of rats for 4 weeks followed by an assessment of memory and learning deficit using behavioral paradigms: Elevated plus maze (EPM), Morris water maze (MWM), and passive avoidance test.

Results: EPS and donepezil showed significant improvement in learning and memory of rats, as indicated by markedly decreased escape latency to reach a hidden platform and increased time spent in target quadrant using MWM task, reduced transfer latency in EPM, and also there is a significant increase in the transfer latencies using passive avoidance test were noted. Memory-enhancing activity of EPS (13.5, 27, and 54 mg/kg) was comparable with the diabetic control group.

Conclusion: The study findings suggest that memory-enhancing effect of EPS may be mediated by its antioxidant and anti-inflammatory activities. This recommends the potential effect of EPS therapy as a useful memory restorative agent in the treatment of neurodegenerative disease seen in type-2 diabetes rat.

Keywords: Type-2 diabetes, Epalrestat, Donepezil, Learning and memory, Morris water maze, Passive avoidance, Elevated plus maze, High-fat diet.

(c) 2018 The Authors. Published by Innovare Academic Sciences Pvt Ltd. This is an open access article under the CC BY license (http://creativecommons. org/licenses/by/4. 0/) DOI: http://dx.doi.org/10.22159/ajpcr.2018.v11i1.23313

\section{INTRODUCTION}

Diabetes mellitus (DM) is the most common endocrine disorder characterized by increased blood glucose levels, resulting from defective insulin secretion, resistance to insulin action, or both. DM is often associated with severe complications, and there is an increasing appreciation that cognitive function declines in DM [1-3]. Chronic hyperglycemia is associated with disturbance of the blood sugar level which leads to nerve cells damage in the brain causing cognitive impairment [4].

Animal studies have shown that high-calorie diets impair the structure and function of the hippocampus, a brain region critical for learning and memory $[5,6]$. In animal models, both type- 1 and type- 2 diabetic animals are reported to induce severe memory deficits $[7,8]$. The increased oxidative stress in diabetes produces oxidative damage in many regions of rat brain including hippocampus.

Oxidative stress and harmful free radicals play an important role in the development of memory impairment. Free radicals and reactive oxygen substances generated by living cells as a result of physiological and biochemical processes and accumulation of these free radicals in the body can cause oxidative damage to lipids, proteins, and DNA, which leads to diabetes and neurodegenerative diseases $[9,10]$.

Epalrestat (EPS) (5-[(1Z,2E)-2-methyl-3-phenyl propenylidene]-4oxo-2-thioxo-3-thiazolidine acetic acid; EPS) is an inhibitor of aldose reductase, well proven to have beneficial effects for the treatment of diabetic neuropathy and is easily absorbed by neural tissue and inhibits aldose reductase with minimum adverse effects [11]. It is reported for anti-inflammatory and antioxidant effects using rat Schwann cell and human neuroblastoma cell line [12-14]. Therefore, the antiinflammatory and anti-oxidant properties of EPS can be beneficial in the management of neurodegenerative disease by improving the memory and learning in an animal model. However, there are no study reports regarding the effect of EPS such as compound on memory and learning in diabetes. In the present study, the effect of EPS was evaluated experimentally with regard to learning and memory in rats.

\section{METHODS}

\section{Animals}

Male Wistar rats (150-200 g) were procured from the central animal house facility of Jawaharlal Nehru Medical College, Belagavi. The rats were acclimatized to $12: 12 \mathrm{~h}$ light-dark cycle for 7 days, before an animal study. They were maintained at constant room temperature $\left(22^{\circ} \mathrm{C}-25^{\circ} \mathrm{C}\right)$ and on standard chow pellet (Amrut Brand) with water ad libitum. The animals were housed in polypropylene cages with 3 animals per cage. The study was approved by the Institutional Animal Ethics Committee constituted as per the guidelines of Committee for the Purpose of Control and Supervision of Experiments on Animals (Resolution No.: 7/D; dated 18.05.2016).

\section{Drugs and solutions}

EPS (Micro Labs Ltd., India), streptozotocin (STZ) (Enzo Life Sciences, UK), donepezil hydrochloride (Alkem Laboratories Ltd., India), and Glucometer/strips (Accu Chek: Roche Diagnostics India Pvt., Ltd., Mumbai) were used. EPS was suspended in $1 \%$ gum acacia, whereas, 
STZ and donepezil hydrochloride were dissolved in citrate buffer (pH 4.4) and distilled water, respectively. Drug solutions/suspensions were prepared fresh before administration. EPS at doses of 57, 27, and $13.5 \mathrm{mg} / \mathrm{kg}$, p.o. and donepezil hydrochloride $1 \mathrm{mg} / \mathrm{kg}$, p.o. were selected on the basis of previous literature and as per human dose [11,15,16-18]. The clinically equivalent human doses of drugs were converted into rat equivalent doses by the conversion table devised by Paget and Barnes [19].

\section{Experimental induction of diabetes}

Type-2 diabetes was induced in rats by previously described methods $[20,21]$. The rats were fed with a high-fat diet (HFD) (VRK Nutritional Solutions, Pune, India) for the initial period of 2 weeks followed by low dose ofSTZ ( $35 \mathrm{mg} / \mathrm{kg}$; i.p) was administered. All diabetic rats were given $5 \%$ glucose solution to prevent from hypoglycemic shock, wherea, normal control (NC) rats were administered with vehicle (1 ml/kg; p.o.). The fasting blood glucose was measured $48 \mathrm{~h}$ after STZ injection. The rats injected with STZ showing fasting blood glucose $>200 \mathrm{mg} / \mathrm{kg}$ noted as diabetic and used for further study. The HFD composition is given in Table 1.

\section{Treatment schedule}

The confirmation day of diabetes was taken as day 1 of diabetic condition. A total of 60 rats (10 normal; 50 HFD-STZ induced diabetic rats) were used and divided into six groups $(\mathrm{n}=10)$ and received the following treatment:

Group I: NC received known volume of vehicle (1 ml/kg, p.o)

Group II: Diabetic control (DC) - vehicle only (1 ml/kg, p.o)

Group III: Diabetic rats + Donepezil hydrochloride (1 mg/kg, p.o)

Group IV: Diabetic rats + EPS (57 mg/kg, p.o)

Group V: Diabetic rats + EPS (27 mg/kg, p.o)

Group VI: Diabetic rats + EPS (13.5 mg/kg, p.o).

All the drugs were administered orally for 4 weeks. Behavioral tests were carried out at the end of the treatment.

\section{Assessment of cognitive function $[7,22,23]$ \\ Elevated plus maze (EPM)}

The test was used to evaluate spatial long-term memory. The maze has two open and two enclosed arm (OA and EA), and it was elevated $25 \mathrm{~cm}$ above the ground. The behavioral tests were conducted in a quiet room illuminated by a dim light.

\section{Learning protocol}

EA divided into two equal parts. Each individual rat was kept at the end of the $\mathrm{OA}$ on day 1 and initial transfer latency (TL) was recorded. To become habituated with the maze, the animals were allowed to explore the plus maze for $90 \mathrm{~s}$ after reaching the EA. On the $2^{\text {nd }}$ day, $24 \mathrm{~h}$ after the first exposure, TL was again noted. A long latency period to reach EA indicates poor retention compared with significantly shorter latencies

\section{Passive avoidance test (step through test)}

The passive avoidance apparatus have two chambers, light and dark compartment with grid floor $50 \times 50 \mathrm{~cm}$ and $35 \mathrm{~cm}$ high walls, separated

Table 1: Composition of HFD

\begin{tabular}{ll}
\hline Ingredients & Diet $(\mathbf{g} / \mathbf{k g})$ \\
\hline Powdered NPD & 365 \\
Lard & 310 \\
Casein & 250 \\
Cholesterol & 10 \\
Vitamin and minerals mix & 60 \\
DL-methionine & 03 \\
Yeast powder & 01 \\
Sodium chloride & 01 \\
\hline
\end{tabular}

HFD: High-fat diet, NPD: Normal pellet diet by a wall with a guillotine door $6 \times 6 \mathrm{~cm}$. One of the two chambers was illuminated with $100 \mathrm{~V}$ bulb placed at $150 \mathrm{~cm}$ height, and the other was dark. The test was conducted on 3 consecutive days at the same time of the day. On day 1 (trial 1) and day 2 (trial 2, 3, and 4), acquisition trial was conducted, and individual rat was kept in illuminated chamber of the apparatus. At the end of the $3^{\text {rd }}$ trial as soon as rat entered the dark compartment, it received an electric shock on the feet $(50 \mathrm{~V}, 50 \mathrm{~Hz}$, $1 \mathrm{~s})$ through the stainless steel grid floor. The time when rat entered in the dark chamber was noted as step-through latency (STL). Retention was tested after $24 \mathrm{~h}$, and STL was recorded. Cutoff time allotted was $300 \mathrm{~s}$. Increase in the STL was considered as an index of improvement of memory.

\section{Morris water maze test (MWM)/spatial discrimination}

During spatial discrimination, the hidden platform was kept at $1.5 \mathrm{~cm}$ below the water level changing the area of the pool from that used during cue discrimination training. We added milk to make the pool water opaque, in which platform shown invisible. The platform has fixed in one place. Rats had trained to four consecutive trials each day for 4 consecutive days. Each trial was given 120 s. Rats were allowed to start swimming in each trial from one of the four locations (north, south, east, and west); the choice of the location was random for each rat and each trial. The rat should escape to the platform within $120 \mathrm{~s}$, and if that did not occur, we guided them gently toward the hidden platform where they remained for $10 \mathrm{~s}$. Probe trial conducted on the $5^{\text {th }}$ day in which platform was removed from the swimming pool and allowed the rat to swim freely for $120 \mathrm{~s}$, and time spent in target location was noted as a function of memory.

\section{Statistical analysis}

The study results were expressed as mean \pm standard error of mean. Data were analyzed using one-way ANOVA followed by Dunnett's multiple comparison test. $p<0.05$ was considered as statistically significant.

\section{RESULTS}

\section{Blood glucose levels}

At the onset of the study, all experimental animals had equivalent blood glucose levels (Table 2). At the conclusion of the experiment, glucose concentrations were highly significantly elevated in donepezil $1 \mathrm{mg} / \mathrm{kg}$ and EPS-treated animals relative to those in the NC.

\section{Effect of EPS on performance of EPM}

The effect of donepezil and EPS treatments in diabetic rats on mean transfer latencies in the EPM test is shown in Fig. 1. Statistical analysis revealed that chronic treatment with donepezil $1 \mathrm{mg} / \mathrm{kg}$ and EPS $(57,27 \mathrm{mg} / \mathrm{kg})$ had a significant effect on the transfer latencies on day 1 (day 29) as compared with DC $(\mathrm{p}<0.001) .0 n$ the day 2 (day 30$)$, HFD-STZ induced TL was drastically decreased when compared to the day 1 . This clearly indicates the learning behavior of animals on the day 2, whereas there was no difference in TL tested on day 1 and 2 in DC animals. On the other hand, cholinesterase inhibitor, donepezil showed a significant reversal of HFD-STZ induced deficits. However,

Table 2: Blood glucose levels (means \pm SEM) in the six groups of rats at the onset and at the end of the experiment

\begin{tabular}{lll}
\hline Treatment & \multicolumn{2}{l}{ Glucose $\mathbf{~ m g} / \mathbf{d l}$} \\
\cline { 2 - 3 } & Onset of the study & End of the study \\
\hline NC & $96.50 \pm 1.48$ & $100.2 \pm 3.16$ \\
DC & $98.11 \pm 4.69$ & $456.4 \pm 11.44^{* * *}$ \\
DC+Donepezil 1 & $100.8 \pm 4.78$ & $411.6 \pm 14.72^{* * *}$ \\
DC+EPS 54 & $97.20 \pm 3.83$ & $396.1 \pm 20.85^{* * *}$ \\
DC+EPS 27 & $100.2 \pm 3.99$ & $404.4 \pm 17.43^{* * *}$ \\
DC+EPS 13.5 & $99.89 \pm 4.67$ & $413.7 \pm 10.94^{* * *}$ \\
\hline
\end{tabular}

DC: Diabetic control, NC: Normal control, EPS: Epalrestat, SEM: Standard error of mean, $n=10$, Data expressed in mean \pm SEM, statistical analysis by one-way ANOVA followed by Dunnett's test. Significance at ${ }^{* * *} \mathrm{p}<0.001$ versus NC group 
donepezil and EPS-treated animals (57, 27, and $13.5 \mathrm{mg} / \mathrm{Kg}$ ) showed significant decreased TL when compared to DC on day 2.

Effect of EPS treatment on TL (passive avoidance test)

In the present study, we used passive avoidance task to assess shortterm/long-term memory for evaluating the effect of EPS. Memory performance was correlated with the latency to escape from the light compartment, the better the recollection, and the greater the latency.

\section{Acquisition}

There was no significant difference in the STLs among the treatments and DC group of rats in the first acquisition trial (before receiving the electrical shock) (Table 3). This observation designates that the exploratory behavior of the different groups of rats in the dark did not differ. However, significant differences were observed among the different experimental groups with respect to the number of trials to acquisition criterion $(p<0.001, p<0.01)$ (Fig. 2 and Table 3$)$. Specifically, the number of trials to acquisition in donepezil-treated group $(\mathrm{p}<0.001$, $\mathrm{p}<0.01)$ and EPS-treated group $(\mathrm{p}<0.001, \mathrm{p}<0.01)$ were significantly less than DC group. Consistent with the presence of a cognitive deficit, the number of trials to acquisition in DC group was significantly greater than $\mathrm{NC}$ group $(\mathrm{p}<0.001)$.

\section{Retention}

In the retention test which was conducted $24 \mathrm{~h}$ after the aversive stimuli (foot shock), retention of memory was significantly decreased in DC group $(\mathrm{p}<0.001)$ as compared to NC group, whereas significantly enhanced TLs were observed in the animals treated with donepezil and EPS $(54,27 \mathrm{mg} / \mathrm{kg} ; \mathrm{p}<0.001, \mathrm{p}<0.01)$ in comparison to DC group.

Effects of EPS treatment on spatial memory deficits in the MWM tasks

The memory impairment was assessed using MWM task. The mean escape latency time was measured to assess spatial memory in the experimental rats. The treatment with donepezil and EPS during training session significantly influenced the escape latency (Table 4 and Fig. 3). Further, statistical analysis revealed that donepezil and higher dose of EPS $(54 \mathrm{mg} / \mathrm{Kg})$ significantly reduced $(\mathrm{P}<0.05)$ escape latency over the course of the training sessions when compared to the DC group. In the spatial probe test, performed on day 5 (day 38), the time spent within the target quadrant by the DC group was decreased as compared to those of the NC group ( $\mathrm{p}<0.001)$ (Fig. 3). Moreover, animals treated with EPS (27 and $54 \mathrm{mg} / \mathrm{kg}$ ) resulted in enhanced time spent within the target quadrant as compared to DC groups $(\mathrm{p}<0.001)$. These effects of EPS were similar to that shown by donepezil treatment $(p<0.001)$.

\section{DISCUSSION}

The study was designed and evaluated for the effect of EPS in diabetesinduced memory impairment: Memory and learning in rats. Type-2 diabetic rats exhibited marked impairment in memory that was revealed with behavioral parameters: EPM, passive avoidance test, and MWM task. Concomitant treatment with EPS, an aldose reductase inhibitor, responds the behavioral changes induced by diabetes.

Earlier studies directed that HFD in combination with a low dose of STZ induces type-2 diabetes [21]. Results of the present study showed the similar effect as well as diabetic rat indicates spatial memory and learning deficits in MWM task.

This was substantiated by the study results in the EPM and passive avoidance task, which was associated with avoided and reversed impairment by EPS treatment in rats. In the present study, we used MWM task to test spatial memory by observing the escape latency to reach a hidden platform. The diabetic rats were severely impaired as compared with $\mathrm{NC}$ rats, confirming earlier findings [24]. Furthermore, rats treated with donepezil and higher dose of EPS learned the platform location faster than diabetes control rats, and these findings were persistent throughout the trials. In addition, enhanced time

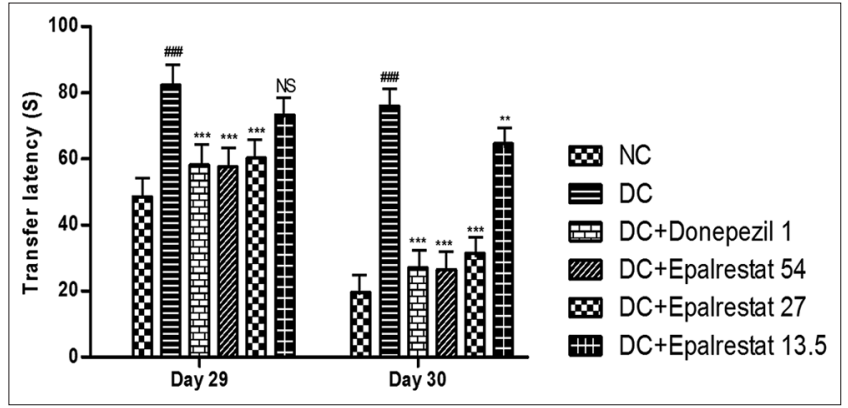

Fig. 1: Effect of EPS on transfer latency in high-fat diet streptozotocin-induced memory impairment on elevated plus maze: DC: Diabetic control, NC: Normal control, EPS: Epalrestat, $S$ : Seconds SEM: Standard error of mean, $\mathrm{n}=10$, Data expressed in mean \pm SEM, statistical analysis by one-way ANOVA followed by Dunnett's test. Significance at ${ }^{* *} \mathbf{p}<0.01,{ }^{* * *} \mathrm{p}<0.001$, ns: Not significant versus DC group and $\# \# \#<0.001$ versus NC group

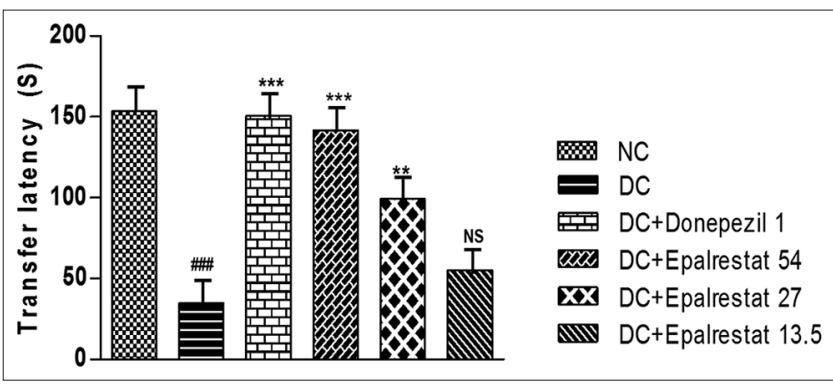

Fig. 2: Effect of EPS on transfer latency in high-fat diet streptozotocin-induced memory impairment on passive avoidance test: DC: Diabetic control, NC: Normal control,

EPS: Epalrestat, S: Seconds, SEM: Standard error of mean, $n=10$, Data expressed in mean \pm SEM, statistical analysis by one-way ANOVA followed by Dunnett's test. Significance at $* * \mathbf{p}<0.01$, *** $\mathbf{p}<0.001$, ns: Not significant versus DC group and ${ }^{\# \#} p<0.001$ versus NC group

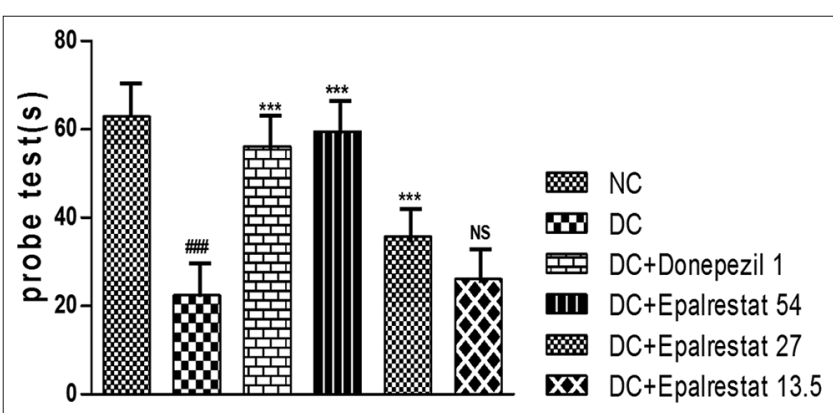

Fig. 3: Effect of EPS on probe test in Morris water maze task in high-fat diet streptozotocin-induced memory impairment rats: DC: Diabetic control, NC: Normal control, EPS: Epalrestat, $S$ : Seconds, SEM: Standard error of mean, $n=10$, Data expressed in mean \pm SEM, statistical analysis by one-way ANOVA followed by Dunnett's test. Significance at ${ }^{* * *} \mathbf{p}<0.001, \mathrm{~ns}$ : Not significant versus DC group and ${ }^{\# \# \#} \mathbf{p}<0.001$ versus NC group

spent in target quadrant in experimental rats treated with donepezil and higher dose of EPS was also revealed in the similar fashion suggesting their motor performance (ability to swim) was unaffected by diabetic condition. In a passive avoidance test, a significant increase in TL time (TLT) as compared with DC (STZ treated) directs successful learning and memory function in EPS-treated rats, whereas STZ-treated rats failed to demonstrate an increase in TLT in retention 
Table 3: Effect of EPS on HFD-STZ-induced memory impairment in the passive avoidance test

\begin{tabular}{|c|c|c|c|c|c|}
\hline \multirow[t]{3}{*}{ Treatment } & \multicolumn{4}{|c|}{ Time taken to enter small compartment (s) } & \multirow[t]{2}{*}{ Day 33} \\
\hline & \multirow{2}{*}{$\begin{array}{l}\text { Day } 31 \\
\text { Trial } 1\end{array}$} & \multicolumn{3}{|l|}{ Day 32} & \\
\hline & & Trial 2 & Trial 3 & Trial 4 & TL \\
\hline $\mathrm{NC}$ & $55.50 \pm 6.77$ & $36.10 \pm 5.42$ & $27.90 \pm 5.31$ & $18.40 \pm 3.18$ & $153.5 \pm 15.93$ \\
\hline DC & $114.4 \pm 5.86$ & $99.89 \pm 6.85^{\# \# \#}$ & $73.33 \pm 6.27^{\# \# \#}$ & $66.89 \pm 6.48^{\# \# \#}$ & $34.78 \pm 3.97$ \#\#\# \\
\hline DC+Donepezil 1 & $99.56 \pm 3.31$ & $55.56 \pm 5.40 * * *$ & $35.22 \pm 4.58^{* *}$ & $23.33 \pm 2.90 * * *$ & $150.6 \pm 17.86^{* * *}$ \\
\hline DC+EPS 54 & $101.5 \pm 2.63$ & $52.70 \pm 8.40^{* * *}$ & $33.50 \pm 7.89 * * *$ & $19.10 \pm 3.31^{* * *}$ & $141.6 \pm 13.49^{* * *}$ \\
\hline DC+EPS 13.5 & $124.9 \pm 3.52$ & $100.2 \pm 4.98^{\mathrm{ns}}$ & $68.33 \pm 4.12^{\mathrm{ns}}$ & $57.00 \pm 4.87^{\mathrm{ns}}$ & $54.89 \pm 6.52^{\mathrm{ns}}$ \\
\hline
\end{tabular}

DC: Diabetic control, NC: Normal control, EPS: Epalrestat, S: Seconds, SEM: Standard error of mean, n=10, Data expressed in mean \pm SEM, statistical analysis by oneway

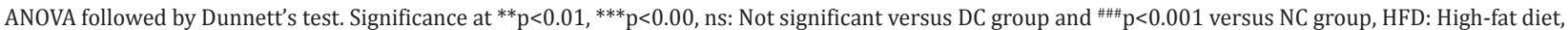
STZ: Streptozotocin, TL: Transfer latency

Table 4: Effect of EPS on spatial memory in MWM task in HFD-STZ induced memory impairment rats

\begin{tabular}{lllll}
\hline Treatment & \multicolumn{2}{l}{ Time taken to reach target platform (s) } & & \multicolumn{2}{c}{$\begin{array}{l}\text { Probe test: Time spent } \\
\text { in target quadrant (s) }\end{array}$} \\
\cline { 2 - 5 } & Day 34 & Day 35 & Day 36 & Day 37 \\
\hline NC & $45.80 \pm 7.79$ & $36.80 \pm 5.68$ & $30.23 \pm 5.25$ & $17.63 \pm 2.78$ \\
DC & $85.00 \pm 2.79^{\# \#}$ & $82.22 \pm 6.05^{\# \#}$ & $72.81 \pm 12.49^{\#}$ & $63.25 \pm 10.58^{\# \#}$ \\
DC+Donepezil 1 & $50.53 \pm 10.08^{*}$ & $43.28 \pm 9.74^{*}$ & $34.86 \pm 12.07^{*}$ & $27.50 \pm 7.18^{*}$ \\
DC+EPS 54 & $48.58 \pm 9.48^{*}$ & $40.45 \pm 10.31^{*}$ & $31.33 \pm 7.17^{*}$ & $22.44 \pm 1.28^{\# \# \#}$ \\
DC+EPS 27 & $57.40 \pm 9.85^{\text {ns }}$ & $52.75 \pm 10.88^{\text {ns }}$ & $38.35 \pm 9.18^{\text {ns }}$ & $35.73 \pm 8.40^{\text {ns }}$ \\
DC+EPS 13.5 & $82.69 \pm 3.39^{\text {ns }}$ & $79.56 \pm 7.64^{\text {ns }}$ & $70.44 \pm 9.38^{\text {ns }}$ & $53.44 \pm 7.61^{\text {ns }}$ \\
\hline
\end{tabular}

DC: Diabetic control, NC: Normal control, EPS: Epalrestat, S: Seconds, SEM: Standard error of mean, $n=10$, Data expressed in mean \pm SEM, statistical analysis by one-way ANOVA followed by Dunnett's test. Significance at ${ }^{*} \mathrm{p}<0.05,{ }^{* *} \mathrm{p}<0.01,{ }^{* * *} \mathrm{p}<0.001$, ns: Not significant versus DC. \#p $<0.05$, ${ }^{\# \#} \mathrm{p}<0.01$, ${ }^{\# \#} \mathrm{p}<0.001$ versus NC. HFD: High-fat diet, STZ: Streptozotocin, MWM: Morris water maze

trial. As per earlier findings, donepezil administrations before trials in STZ-induced rats attenuated the memory impairment from $2^{\text {nd }}$ trial onward [25]. In similar manner, treatment with EPS also attenuated the memory impairment from $2^{\text {nd }}$ trial onward. These results confirm the previous study findings that have shown cognitive impairment in STZ-induced diabetic rats, which is associated with hippocampal dysfunction [26-28].

In our study, the EPM, passive avoidance, and MWM were used for the assessment of learning and memory. We evaluated the EPS treatment orally for 4 weeks improved learning and memory. All the doses of EPS improved the memory, as reflected by the diminished TL compared with diabetic rat, and decreased latency time in all repeated trials in MWM indicates learning and memory function, whereas decreased TL in EPM and increased TL during retention trial in PAT test showed improvement of memory.

Previous studies reported that decreased TLT in the $2^{\text {nd }}$ day compared to $1^{\text {st }}$ day in EPM indicated retention of memory $[29,30]$. The treatment with donepezil and EPS in experimental rats revealed that significant decreased TL on $2^{\text {nd }}$ day trial $\left(30^{\text {th }}\right.$ day $)$ as compared to $1^{\text {st }}$ day trial $\left(29^{\text {th }}\right.$ day). This finding indicated memory retention in treated rats. In several studies, these cognitive deficits in diabetes were correlated for probable mechanisms such as hyperglycemiainduced end-organ neuronal damage, dyslipidemia, amyloidopathy, and tauopathy $[31,32]$.

In the present study, EPS treatment significantly improved learning and memory impairment in HFD-STZ-induced diabetic rats using behavioral parameters. On the other hand, EPS treatment had no effect on blood glucose levels during the study, suggesting that there is no antidiabetic effect of EPS in experimental rats. This is also supported by earlier reports for blood glucose levels on EPS treatment [18]. Oxidative stress is considered to play a fundamental role in the development of memory impairment in diabetes [33,34]. EPS increases the intracellular levels of glutathione (GSH) which plays a crucial role in protecting endothelial cells from oxidative stress, thereby preventing several vascular diseases caused by oxidative stress [13]. These observations suggest that EPS have significant antioxidant activity against STZinduced oxidative stress [14]

STZ-induced diabetes was used in the present study because it is a wellknown model of experimental diabetes and provides a good and relevant example of chronic oxidative stress due to hyperglycemia [26,35]. In addition, there are several potential explanations for polyol pathwayinduced increase in oxidative stress. Hyperglycemia activates the polyol pathway, and reduction of glucose to sorbitol through aldose reductase may lead to NADPH consumption [36]. As NADPH is used in several critical reductive metabolic steps, a large drain on the NADPH pool could compromise the ability of the cell to protect itself from oxidative stress. NADPH is also required for GSH reductase to regenerate GSH [37-40]. Considering the importance of oxidative stress in the pathophysiology of diabetic state and development of cognitive impairment, reduction of oxidative stress by EPS may produce a beneficial effect on diabeticinduced cognitive impairment.

Neuroinflammatory mediators and oxidative stress markers are capable in causing cognitive alterations through several mechanisms that could possibly affect the neuronal properties and cell survival. Several studies were conducted earlier to conceptualize the possible cause and link between neuroinflammation, oxidative stress, behavior, and cognitive impairments [34,41-43].

According to the previous findings, heme oxygenase (HO)-1 has potent antioxidant and anti-inflammatory functions; however, EPS upregulates HO-1, dismutase, and catalase by activating Nrf2 and suggests that EPS has the beneficial effect on improvement of several neurological disorders [12].

Interestingly, a recent in vitro study reported that EPS treatment on rat Schwann cells and human neuroblastoma cell line upregulates HO-1 suggesting the potential of EPS to prevent neurological diseases. Therefore, a pilot study was conducted by us to analyze behavioral effects in EPS-treated rats using STZ-HFD induced model. 


\section{CONCLUSION}

Based on our results obtained in the present study, the EPS has shown enhanced learning and memory activity. In particular, it was more significant at the dose of 27 and $57 \mathrm{mg} / \mathrm{kg}$. However, further extensive studies are needed to establish its exact mechanism of action for potent and efficacious agent in the treatment of memory deficit.

\section{REFERENCES}

1. Reynolds RM, Strachan MW, Labad J, Lee AJ, Frier BM, Fowkes FG, et al. Morning cortisol levels and cognitive abilities in people with Type 2 diabetes: The Edinburgh Type 2 diabetes study. Diabetes Care 2010;33:714-20.

2. van den Berg E, Kloppenborg RP, Kessels RP, Kappelle LJ, Biessels GJ. Type 2 diabetes mellitus, hypertension, dyslipidemia and obesity: A systematic comparison of their impact on cognition. Biochim Biophys Acta 2009;1792:470-81.

3. Wrighten SA, Piroli GG, Grillo CA, Reagan LP. A look inside the diabetic brain: Contributors to diabetes-induced brain aging. Biochim Biophys Acta 2009;1792:444-53.

4. Vijayakumar TM, Sirisha GB, Begam F, Dhanaraju MD. Mechanism linking cognitive impairment and diabetes mellitus. Eur J Appl Sci 2012;4:1-5.

5. Greenwood CE, Winocur G. Learning and memory impairment in rats fed a high saturated fat diet. Behav Neural Biol 1990;53:74-87.

6. Eichenbaum H, Schoenbaum G, Young B, Bunsey M. Functional organization of the hippocampal memory system. Proc Natl Acad Sci U S A 1996;93:13500-7.

7. Bhutada P, Mundhada Y, Bansod K, Bhutada C, Tawari S, Dixit P, et al. Ameliorative effect of quercetin on memory dysfunction in streptozotocin-induced diabetic rats. Neurobiol Learn Mem 2010;94:293-302.

8. Bhutada P, Mundhada Y, Bansod K, Tawari S, Patil S, Dixit P, et al. Protection of cholinergic and antioxidant system contributes to the effect of berberine ameliorating memory dysfunction in rat model of streptozotocin-induced diabetes. Behav Brain Res 2011;220:30-41.

9. Baydas G, Canatan H, Turkoglu A. Comparative analysis of the protective effects of melatonin and Vitamin E on streptozocin-induced diabetes mellitus. J Pineal Res 2002;32:225-30.

10. Hawkins CL, Davies MJ. Generation and propagation of radical reactions on proteins. Biochim Biophys Acta 2001;1504:196-219.

11. Hotta N, Sakamoto N, Shigeta Y, Kikkawa R, Goto Y. Clinical investigation of epalrestat, an aldose reductase inhibitor, on diabetic neuropathy in japan: Multicenter study. Diabetic neuropathy study group in japan. J Diabetes Complications 1996;10:168-72.

12. Yama K, Sato K, Murao Y, Tatsunami R, Tampo Y. Epalrestat upregulates heme oxygenase-1, superoxide dismutase, and catalase in cells of the nervous system. Biol Pharm Bull 2016;39:1523-30.

13. Sato K, Yama K, Murao Y, Tatsunami R, Tampo Y. Epalrestat increases intracellular glutathione levels in schwann cells through transcription regulation. Redox Biol 2013;2:15-21.

14. Ohmura C, Watada H, Azuma K, Shimizu T, Kanazawa A, Ikeda F, et al. Aldose reductase inhibitor, epalrestat, reduces lipid hydroperoxides in Type 2 diabetes. Endocr J 2009;56:149-56.

15. Tripathi K D. Essentials of Medical Pharmacology. $6^{\text {th }}$ ed. New Delhi: Jaypee Brothers medical Publishers; 2010. p. 99.

16. Sweetman SC. Martindale the Complete Drug Reference. $36^{\text {th }}$ ed., Vol. 1. UK. RPS Publications; 2009. p. 439.

17. Yang Q, Kaji R, Takagi T, Kohara N, Murase N, Yamada Y, et al. Abnormal axonal inward rectifier in streptozocin-induced experimental diabetic neuropathy. Brain 2001;124:1149-55.

18. Mizuno K, Kato N, Makino M, Suzuki T, Shindo M. Continuous inhibition of excessive polyol pathway flux in peripheral nerves by aldose reductase inhibitor fidarestat leads to improvement of diabetic neuropathy. J Diabetes Complications 1999;13:141-50.

19. Ghosh MN. Fundamentals of Experimental Pharmacology. $3^{\text {rd }}$ ed. Kolkata: Hilton \& Company; 2005

20. Rahigude A, Bhutada P, Kaulaskar S, Aswar M, Otari K. Participation of antioxidant and cholinergic system in protective effect of naringenin against Type-2 diabetes-induced memory dysfunction in rats. Neuroscience 2012;226:62-72.

21. Srinivasan K, Viswanad B, Asrat L, Kaul CL, Ramarao P. Combination of high-fat diet-fed and low-dose streptozotocin-treated rat: A model for Type 2 diabetes and pharmacological screening. Pharmacol Res 2005;52:313-20

22. Rajashree R, Kholkute SD, Goudar SS. Effects of duration of diabetes on behavioural and cognitive parameters in streptozotocin-induced juvenile diabetic rats. Malays J Med Sci 2011;18:26-31.

23. Rajashree R, Kholkute SD, Goudar SS. Effects of duration of diabetes on cognitive functions in streptozotocin induced young diabetic rats. Al Ameen J Med Sci 2012;5:256-63.

24. Biessels GJ, Kamal A, Urban IJ, Spruijt BM, Erkelens DW, Gispen WH, et al. Water maze learning and hippocampal synaptic plasticity in streptozotocin-diabetic rats: Effects of insulin treatment. Brain Res 1998;800:125-35.

25. Sonkusare S, Srinivasan K, Kaul C, Ramarao P. Effect of donepezil and lercanidipine on memory impairment induced by intracerebroventricular streptozotocin in rats. Life Sci 2005;77:1-4.

26. Amin SN, Younan SM, Oussef MF, Rashed LA, Mohamady I. Effect of diabetes mellitus on rat cognitive functions and related hippocampal synaptic plasticity markers. Med J Cairo Univ 2011;79:213-27.

27. Arvanitakis Z, Wilson RS, Bienias JL, Evans DA, Bennett DA. Diabetes mellitus and risk of alzheimer disease and decline in cognitive function. Arch Neurol 2004;61:661-6

28. Popoviç M, Biessels GJ, Isaacson RL, Gispen WH. Learning and memory in streptozotocin-induced diabetic rats in a novel spatial/object discrimination task. Behav Brain Res 2001;122:201-7.

29. Itoh J, Nabeshima T, Kameyama T. Utility of an elevated plusmaze for the evaluation of memory in mice: Effects of nootropics, scopolamine and electroconvulsive shock. Psychopharmacology (Berl) 1990;101:27-33.

30. Sharma AC, Kulkarni SK. Evaluation of learning and memory mechanisms employing elevated plus-maze in rats and mice. Prog Neuropsychopharmacol Biol Psychiatry 1992;16:117-25.

31. Holmes CS, Hayford JT, Gonzalez JL, Weydert JA. A survey of cognitive functioning at difference glucose levels in diabetic persons. Diabetes Care 1983;6:180-5.

32. Kim B, Backus C, Oh S, Hayes JM, Feldman EL. Increased tau phosphorylation and cleavage in mouse models of Type 1 and Type 2 diabetes. Endocrinology 2009;150:5294-301.

33. Kucukatay V, Ağar A, Gumuslu S, Yargiçoğlu P. Effect of sulfur dioxide on active and passive avoidance in experimental diabetes mellitus: Relation to oxidant stress and antioxidant enzymes. Int J Neurosci 2007;117:1091-107.

34. Vangalapati B, Manjrekar PA, Hegde A, Kumar A. Pterocarpus marsupium heartwood extract restores learning, memory and cognitive flexibility in a STZ-NA induced diabetes animal model. Int J Pharm Pharm Sci 2016;8:339-43.

35. Low PA, Nickander KK, Tritschler HJ. The roles of oxidative stress and antioxidant treatment in experimental diabetic neuropathy. Diabetes 1997;46 Suppl 2:S38-42

36. Barnett PA, González RG, Chylack LT Jr., Cheng HM. The effect of oxidation on sorbitol pathway kinetics. Diabetes 1986;35:426-32.

37. Obrosova IG, Minchenko AG, Vasupuram R, White L, Abatan OI, Kumagai AK, et al. Aldose reductase inhibitor fidarestat prevents retinal oxidative stress and vascular endothelial growth factor overexpression in streptozotocin-diabetic rats. Diabetes 2003;52:864-71.

38. Gonzalez AM, Sochor M, Hothersall JS, McLean P. Effect of aldose reductase inhibitor (sorbinil) on integration of polyol pathway, pentose phosphate pathway, and glycolytic route in diabetic rat lens. Diabetes 1986;35:1200-5.

39. Yeh LA, Ashton MA. The increase in lipid peroxidation in diabetic rat lens can be reversed by oral sorbinil. Metabolism 1990;39:619-22

40. Takebe G, Yarimizu J, Saito Y, Hayashi T, Nakamura H, Yodoi J, et al. A comparative study on the hydroperoxide and thiol specificity of the glutathione peroxidase family and selenoprotein P. J Biol Chem $2002 ; 277: 41254-8$

41. Magaki S, Mueller C, Dickson C, Kirsch W. Increased production of inflammatory cytokines in mild cognitive impairment. Exp Gerontol 2007; $42: 233-40$.

42. Holmes C, Cunningham C, Zotova E, Woolford J, Dean C, Kerr S, et al. Systemic inflammation and disease progression in alzheimer disease. Neurology 2009;73:768-74.

43. Gourigari TR, Lepakshi BM, Kamsala RV, Raju RR. Evaluation of anticholinergic, antidiabetic and antioxidant activity of leaf extracts of Ochna obtusata DC using in vitro assays. Int J Pharm Pharm Sci 2016;8:82-7. 